\title{
INVESTIGATION OF TEXTILE HEATING ELEMENT IN SIMULATED WEARING CONDITIONS
}

\author{
Laimutè Stygiene் ${ }^{1}$, Sandra Varnaitė-Žuravliova ${ }^{2, *}$, Aušra Abraitiené3 ${ }^{3}$ Ingrida Padleckiené ${ }^{3}$, Sigitas Krauledas ${ }^{3}$ \\ 1 Department of Technological Development of Textile, Center for Physical Sciences and Technology (FTMC), Demokraty str. 53, Kaunas, Lithuania \\ 2 Department of Textiles Physical-Chemical Testing, Center for Physical Sciences and Technology (FTMC), Demokraty str. 53, Kaunas, Lithuania \\ 3 Department of Textile Technologies, Center for Physical Sciences and Technology (FTMC), Demokraty str. 53, Kaunas, Lithuania \\ ${ }^{*}$ Corresponding author. E-mail: sandra.varnaite.zuravliova@ftmc.lt
}

\begin{abstract}
:
The research was focused on the heating capacity of developed, isolated from water penetration, knitted textile heating element with incorporated conductive silver (Ag)- plated yarns, which can be used in manufacturing heating textile products intended for recreation, sports, or health care for elderly. The aim of the investigation was to obtain an appropriate temperature on a human skin, generated by the textile heating element surface at a lower voltage depending on a variety of wearing conditions indoor. Depending on the supplied voltage to the heating element, an incoming electric energy can be converted into different heat. Therefore, the electrical and achieved temperature parameters of heating elements are very important by selecting and adapting required power source devices and by setting the logical parameters of programmable controllers. The heating-cooling dynamic process of developed textile heating element was investigated at different simulated wearing conditions on a standard sweating hot plate and on a human skin at applied voltages of $3 \mathrm{~V}$ and $5 \mathrm{~V}$. It was discovered that a voltage of $5 \mathrm{~V}$ is too big for textile heating elements, because the reached steady state temperature increases to approximately $39-40^{\circ} \mathrm{C}$, which is too hot for contact with the human skin. The voltage of $3 \mathrm{~V}$ is the most suitable to work properly and continuously, i.e., to switch on when the adjusted temperature is too low and to turn off when the necessary temperature is reached. Based on the values of reached steady-state heating temperature, the influence of the applied voltage, ambient air flow velocity, and heating efficiency, depending on various layering of clothes, was determined. Recorded temperatures on the external surface of the heating element provided the possibility to assess its heat loss outgoing into the environment. It was suggested that heat loss can be reduced by increasing thermal insulation properties of the outer layer of the heating element or using layered clothing. On the basis of the resulted heating characteristics, recommended parameters of power source necessary for wearable textile heating element were defined.
\end{abstract}

\section{Keywords:}

Textile heating element, heating efficiency, thermocouple sensors, temperature parameters

\section{Introduction}

The general principles, definitions, and categories of smart textiles are described in the document CEN/TR 16298 [1]. The main components of the wearable intelligent textile system (ITS) are an actuator associated with a specific purpose sensor, an electronic information controller (processor), an energy source, and a communication device. An example of the simplified principle scheme of ITS is presented in Figure 1.

Modern intelligent clothing, as compared to the traditional one, has additional active features. These features provide the use of textile materials with unique properties, integrated wearable electronic devices, or a combination of both [2, 3]. According to the nature of intelligence, clothing can be divided into three levels [4]:

- as an "assistant" who collects and stores certain information and processes the data received;

- as an "observer" who records human physiological parameters and follows the state of health;

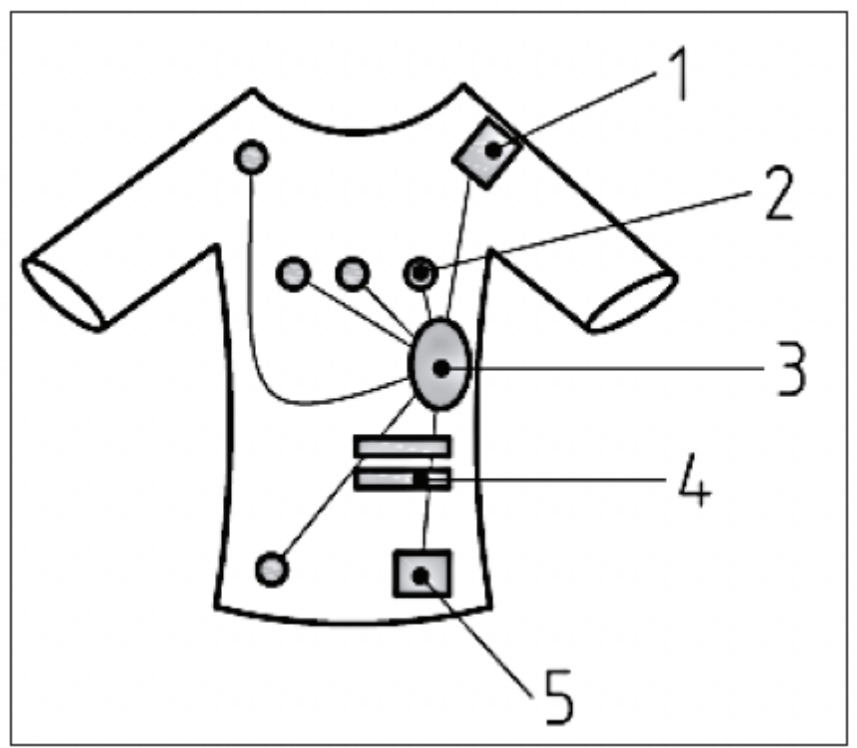

Figure 1. An example of a wearable intelligent textile system: 1 communication; 2 - sensors; 3 - processors; 4 - actuator; and 5 energy supply [1]. 
- as a "regulator" who tracks and adjusts the required parameters. This level includes heating textile products.

Currently, the heating of smart clothing products based on nontextile electronic components (called "wearing electronics") already exists in the market, but these products have not received the wide range of consumers yet.

It is known that a prototype of a heated intelligent clothing product was developed in Finland at Tampere University of Technology in 2006 [5]. The base of the product is a heated shirt with digital temperature sensors measuring wearer's skin and a glowing carbon fiber panel, powered by high-capacity nickel batteries. The heating temperature range can be chosen by the wearer himself. The electronic circuitry and the heating panel must be removed before washing of clothes. The heating element made of carbon fiber is also used by the Milwaukee "M12 ${ }^{\mathrm{TM}}$ Heated Gear" in the production line of protective clothing against foul weather.

The North Face company's heating jacket MET5 is also known in the market. It has two heating zones formed by conductive fibers and maintains the optimum temperature for the wearer by pressing the textile button. This technical solution made in the "Malden Mills" and "The North Face" companies produced heated jacket called Polartec ${ }^{\circledR}$ Heat $^{\mathrm{TM}}$. It was implemented by using a heat-generating network of thin fibers fused to the chest area. All electronic components must be removed before washing.

Heating underwear is manufactured by WarmX $\mathrm{GmbH}$. The main idea of the WarmX technology is to achieve the warmth effect with the lowest possible energy consumption. According to this concept, heating elements are incorporated into underwear, where direct skin contact minimizes energy loss. These garments are produced from knitted fabrics made of conductive silver-plated polyamide yarns.

Textile heating garments (underwear, gloves, socks, waistcoats) are also advertised by companies such as Duran, China Depot, Zanier - Sport $\mathrm{GmbH}$, and Inuheat.

Temperature control is one of the most important functions of clothes. Most of the heating elements use the principle of Joule's heat, which is generated when an electric current is passed through a conductive material. All conductive materials are heating elements in principle. The basis of heating textile products consists of materials that have electrical conductivity properties. Analyzing technical literature and the market for this type of products [1-15], it can be concluded that in recent years clothing products have been designed to integrate heating elements in the material structure, which are composed of conductive yarns introduced in various ways. There are two ways to manufacture heated textiles: (1) produce a technical fabric and then integrate electronic components and (2) produce a technical yarn with electronic features and then to manufacture a textile material of that yarn [7]. It has been indicated in references $[7,16]$ that the resistance of heating panels, produced by weaving, is lower than of knitted structures with the same dimensions because of the structural characteristics: woven fabrics have less surface characters, an quality property, when compared to knitted fabrics and heating elements made of nonwoven. They have proved to be of little use owing to high electrical resistance of conductive nonwoven fabric. So, knits are more appropriate for implications as heating panel. Yarns that have electrical conductivity in their fiber composition by introducing natural conductive additives or special pre-treatment are more suitable for integration into textile materials than metal wire or cable, since they do not limit textile properties (softness, flexibility) [17, 18]. However, it should be noted that yarns obtained by conductive coatings in various ways covering their components tend to have a higher electrical resistance than metals [8]. This needs to be evaluated when designing fabrics for specific conductive applications with intended electrical and thermal efficiency properties.

In the research [6], it was concluded that steel yarns could not be used for knitting, while silver-coated polyamide yarns are suitable for the manufacture of knitted heating elements. Conductive yarns knitted into fabric depending on the yarn type increase or decrease their resistance in relation to initial resistance. Evenness of warm-up was provided by three-ply silver-coated polyamide yarns. The knitted heating element of three-ply yarn performed the heating functions without any significant changes in the temperature over a long period of time. The main criteria for the selection of yarns for the manufacture of knitted resistive heating element are low electrical resistance of yarns, low resistance changes during the elongation of the knitted heating element, temperature evenness of element for a long time and the suitability of yarns for knitting.

A comparison of heat generation by plain, rib and interlock structures was studied in scientific article [7]. It was observed from the series of experiments that a minimum threshold force of contact at binding points of a knitted structure is required to pass the electricity. Once this force is achieved, stretching the fabric does not affect the amount of heat produced.

The paper [19] presented a novel and facile method for fabricating flexible heating fabrics with temperature perception; a temperature-sensitive fine copper was integrated into two pieces of flexible fusible interlining fabrics by a simple thermal bonding method. The electrical properties, thermal performance, and mechanical properties of investigated materials are stable according to the presented experimental data and analysis, and it may be helpful for developing the secure and durable products.

The temperature of the human skin, depending on the environmental conditions, varies in different parts of the body $\left(32-37^{\circ} \mathrm{C}\right)$ [20]. The average human skin temperature is assumed to be about $34^{\circ} \mathrm{C}$ [21]. The researchers of Cornell University (USA) assessed that the maximum temperature attained by the heating elements that come into contact with human skin must not exceed the tolerance limits of the human temperature $\left(40^{\circ} \mathrm{C}\right)[5]$. An exposure to the skin above $40^{\circ} \mathrm{C}$ for a warmer surface for more than 30 seconds has a potentially painful effect. Table 1 presents the conditions for the thermal sensation and human thermophysiological comfort depending on the temperature of the skin. 
Table 1. Dependence of the thermal sensation on the wearer's skin temperature

\begin{tabular}{|c|c|}
\hline Thermal sensation & Temperature of human skin, ${ }^{\circ} \mathbf{C}$ \\
\hline Very hot & $>36.6$ \\
\hline Hot & $36.0 \pm 0.6$ \\
\hline Warm & $34.9 \pm 0.7$ \\
\hline Comfortable & $33.2 \pm 1.0$ \\
\hline Cool & $31.1 \pm 1.0$ \\
\hline Cold & $29.1 \pm 1.0$ \\
\hline Very cold & $<28.1$ \\
\hline
\end{tabular}

In order to avoid the risk of burning of human tissue, the temperature of the heated heating circuit must not exceed $40^{\circ} \mathrm{C}$; the heating must be evenly distributed throughout the heating circuit area. Based on the technical parameters of the heating products in the market, the design of the heating circuit was subject to compliance with the provisions that its total electrical power should not exceed $12 \mathrm{~W}$, which would be sufficient to provide a power supply of $5-7 \mathrm{~V}$.

While designing active clothing, an appropriate distribution of temperatures on the inner side of the clothing should be ensured. The heating system itself does not ensure this distribution, since there are "empty spaces" between heating elements in the system, resulting from the necessity of preserving gap elements of the system in the desirable direction [22].

The application fields developed for this research textile heating element are heating textile products for sports (warming effect is important for people engaged in active sports for the warm-up training phase, which increases muscle efficiency and reduces the risk of injury) [23], recreational activities, or improving health of the elderly or disable people [24, 25]. The novelty of developed heating element for this research is that it has a continuous, homogeneous temperature distribution at a quite large surface area by supplying only $3 \mathrm{~V}$ voltage, while other authors declared not less than 5-7 V, and the lamination finishing protects the heating element not only against water penetration but also from friction process, which can cause the wear down of silver coating from conductive yarns.

During the review of different scientific papers, patents, and industry products, it was not found any other relevant heating element that would be laminated and manufactured in such a way that conductive yarns would not form a "snake" inside the heating element, and there was no information from other authors about the change in skin temperature during investigations of heating elements.

\section{Experimental}

Flexible textile heating element was developed for this research, and its heating capability in different simulated wearing conditions was investigated. The FIHN ("Orizio", Italy) circular knitting machine of $20 \mathrm{E}$ gage was used for the production of electroconductive knitted fabric, which was used for developing heating elements. The detailed description of the finished three-thread fleecy knitted fabric, used to produce the heating element, is given in Table 2, and the knitting structure is shown in Figure 2.

Shieldex ${ }^{\circledR}$ is a conductive yarn (twist direction $Z$, twist level $300 \mathrm{~m}^{-1}$ ) consisting of two twisted components, continuous filament polyester (PET) 11.3 tex ( $\mathrm{f} 32$ ) and PET silver coated 4.4 tex (f12), developed by Statex (Germany). The four-ply (twist direction $S$, twist level $100 \mathrm{~m}^{-1}$ ) 17.0 tex $\mathrm{x}$ four-ply Shieldex ${ }^{\circledR}$ yarns were used in the knitting process. These fleece yarns were manufactured on the $\mathrm{PL} 31 \mathrm{C}$ ring twisting machine. The Mirawave ${ }^{\circledR} 29.4$ tex PET (fibre thickness 1.2 dtex, fibre length $38 \mathrm{~mm}$ ) staple ring - spun yarns (twist direction $Z$, twist level $520 \mathrm{~m}^{-1}$ ) - were produced by Predilnica Litija d.o.o. (Slovenia). It is a trade mark and a brand name for a PET fiber with

Table 2. Description of electroconductive weft knitted fabric used for the heating element

\begin{tabular}{|c|c|c|c|c|c|}
\hline \multirow{2}{*}{ Layers } & \multirow{2}{*}{$\begin{array}{l}\text { Type of yarn, linear density, } \\
\text { tex }\end{array}$} & \multirow{2}{*}{$\begin{array}{l}\text { Arrangement of yarns in } \\
\text { pattern courses (knitting } \\
\text { feeds; see Figure 2) }\end{array}$} & \multicolumn{2}{|c|}{$\begin{array}{l}\text { Number of stitches per unit } \\
\text { length and unit area, } \mathbf{c m}^{-1}\end{array}$} & \multirow{2}{*}{$\begin{array}{l}\text { Mass per } \\
\text { unit area, } \\
\mathrm{g} / \mathrm{m}^{2}\end{array}$} \\
\hline & & & Courses, PV & Wales, PH & \\
\hline I- outer & $\begin{array}{l}\text { Polyester (PET) staple ring - } \\
\text { spun yarns with bio-ceramic } \\
\text { additives Mirawave }{ }^{\circledR}, 29.4\end{array}$ & E2, E5, E8, E11 & \multirow[t]{4}{*}{13} & \multirow[t]{4}{*}{8} & \multirow[t]{4}{*}{370} \\
\hline II - middle & $\begin{array}{c}\text { PET staple ring - spun yarns } \\
\text { with bio-ceramic additives } \\
\text { Mirawave }^{\circledR}, 29.4\end{array}$ & $\mathrm{E} 1, \mathrm{E} 4, \mathrm{E} 7, \mathrm{E} 10$ & & & \\
\hline \multirow[t]{2}{*}{$\begin{array}{l}\text { III - inner } \\
\text { (next to the } \\
\quad \text { skin) }\end{array}$} & $\begin{array}{c}\text { PET/Silver twisted continuous } \\
\text { - filament yarns Shieldex }{ }^{\circledR} \text { [PET } \\
\text { 11.3(f32) + PET silver coated } \\
4.4(\mathrm{f} 12)], 17.0 \times 4 \text { ply }\end{array}$ & E3, E6 & & & \\
\hline & $\begin{array}{c}\text { PET staple ring - spun yarns } \\
\text { with bio-ceramic additives } \\
\text { Mirawave }^{\circledR}, 29.4\end{array}$ & E9, E12 & & & \\
\hline
\end{tabular}

Note: The number of stitches was calculated according to EN 14971 standard, and the mass per unit area was determined according to EN 12127 standard. 


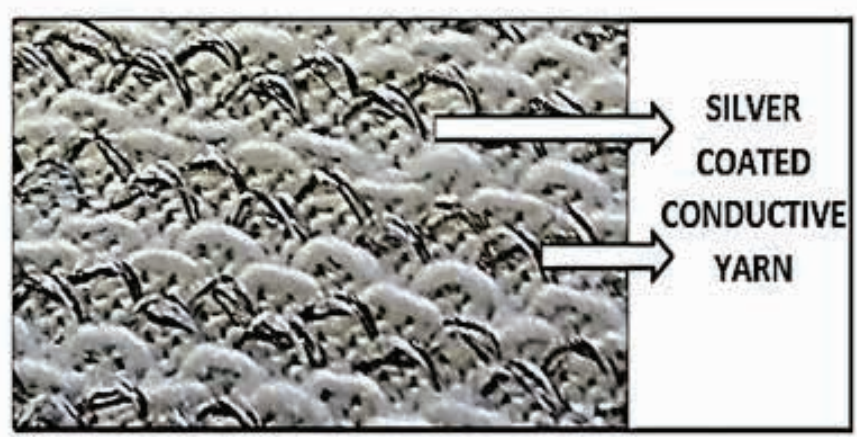

a

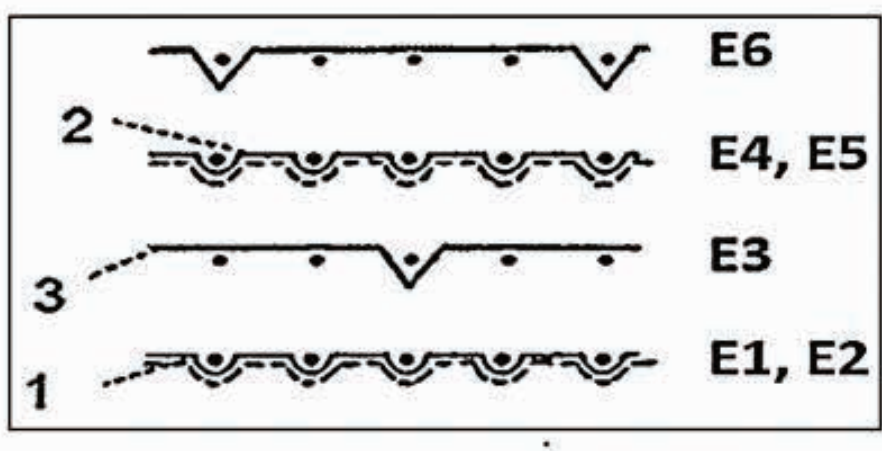

b

Figure 2. View of the structure (a) and a pattern scheme (b) of three-thread fleecy knitted fabric used for the heating element, where 1 represents the plating yarn (outer layer), 2 the binding yarn (middle layer), and 3 the fleece yarn (inner layer).

embedded bio-ceramic additives, developed by Huvis (South Korea).

As it is seen in Figure 2, the electric conductive Shielde ${ }^{\circledR}$ yarns were inserted in the inner side (next to the skin) of the knitted fabric as a tuck loop-float loop.

A heating circuit with a heating area of (length $x$ height) $30 \times 16 \mathrm{~cm}$ was prepared for heat energy efficiency studies (see Figure 3 ). The heating circuit (1) of parallel connected electrically conductive elements (2), formed from the fleece yarns located in the transverse direction, was obtained by attaching two closed pillar stitches (3) in the longitudinal direction in both sides of said knit. The pillar stitch of the heating circuit of parallel connected electrically conductive elements formed from the fleece yarns located in the transverse direction was obtained in both sides of the circuit by attaching the pillar stitch in the longitudinal direction. The pillar stitch was made manually from 30-ply silver-coated continuous filament polyamide (PA/Ag) $45.0 \pm 10$ tex (basic yarn count -23.5 tex, f32, thickness of silver layer $\sim 1 \mu \mathrm{m}$ ) Elitex ${ }^{\circledR}$ (a trademark of IMBUT, Germany) yarns. Two closed pillar stitches were attached with conventional sewing threads using zigzag stitch (stitch length $1.0 \mathrm{~mm}$, width $3.0 \mathrm{~mm}$ ) by a sewing machine LZ-2280AA JUKI (Japan). The water-repellent finishing was performed for knitted heating circuit before isolation of the heating element from penetration of water. For this purpose, the fluorocarbon dispersion based on C-6, known as waterrepellent agent Beiphob FR ( $\mathrm{CHT}$ - Bezema), was sprayed on knitted heating circuit at room temperature. The recipe was as follows: Beiphob FR - $60 \mathrm{~g} / \mathrm{l}, \mathrm{pH}-5.5$. The drying-thermosetting process was carried out in the laboratory oven and steamer machine TFOS IM 350 (Roaches International) at $100-140^{\circ} \mathrm{C}$ for $7 \mathrm{~min}$. The resistance to surface wetting (grade $=6$ ) of the prepared sample was measured according to the LST EN ISO 4920 standard. The isolation of the heating element was carried out using a laboratory dry hot fusing machine Nova-45 (Reliant Machinery Ltd., UK). Later both sides of knitted circuit was laminated with two-layer $92 \mathrm{~g} / \mathrm{m}^{2}$ Polymax $^{\circledR}$ (Polymax Ltd, UK) waterproof composite fabric, consisting of PET hydrophilic membrane and knit. All three layers were laminated using thermoplastic $8 \mathrm{~g} / \mathrm{m}^{2}$ adhesive PA copolymer fabric Texiron ${ }^{\circledR}$ (Protechnic, France). The weight of produced, isolated from water penetration heating element (heating area $-0.16 \mathrm{~m} \mathrm{x}$

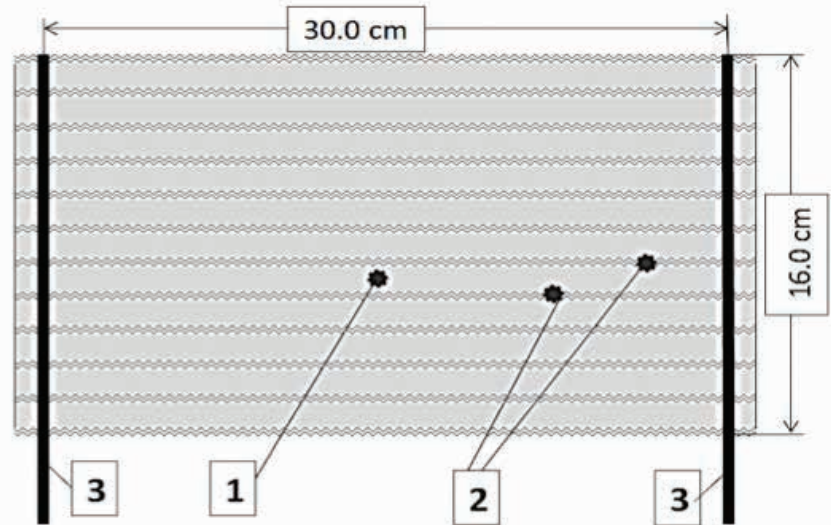

Figure 3. Schematic illustration of the non-isolated heating element: (1) the heating circuit formed on the back side of fleecy knitted fabric, (2) silver coated $17.0 \times 4$ tex polyester yarns, incorporated into the knitting structure, and (3) the pillar stitch from 30-ply silver-coated filament polyamide $45.0 \pm 10$ tex yarns.

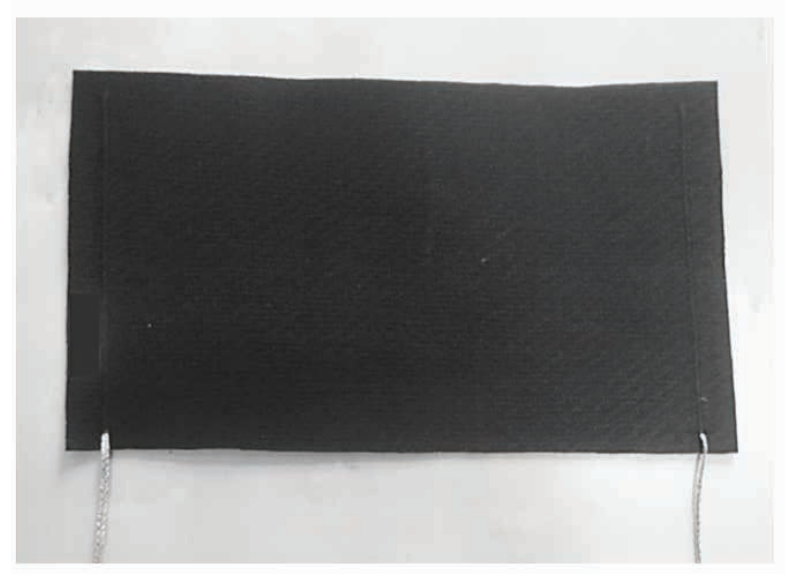

Figure 4. Construction of developed, isolated heating element.

$0.30 \mathrm{~m}^{2}$ ) was $27.4 \mathrm{~g}$ and its electrical resistivity was $1.7857 \Omega$. The general view of the heating element is presented in Figure 4.

The warming-cooling temperature parameters of the heating element were recorded over time at every 10 seconds, at applied voltages of 3 and $5 \mathrm{~V}$, by using a thermocouple type sensors $2 \times$ NTC Type $N$ (measuring range -50 to $+125^{\circ} \mathrm{C}$ ), which were connected with the help of connector ZA $9040 \mathrm{FS}$ to the $A L M E M O{ }^{\circledR} 2470$ series universal measuring instrument 
(Ahlborn Mess- und Regelungstechnik GmbH, Germany) with two measurement inputs and long-term data logger.

When supplying 3 and $5 \mathrm{~V}$ voltages to the heating element, in both cases, after reaching the steady-state temperature of the heating temperature, the direct current source automatically switched off and the temperature parameters of the cooling process were recorded.

One textile heating element was manufactured for the research, but five heating-cooling cycles were performed in order to investigate how it works and to record all necessary experimental data. The mean values out of five cycles were given as a result. The calculated coefficient of variation was $2-3 \%$. So, it was assumed that experimental data are repeatable and there is no need for other statistical calculations.

The principal scheme of these investigations is shown in Figure 5.

In order to evaluate the influence of these conditions, the temperature parameters of the developed heating element were determined in different environments that are in the simulation and real conditions of operation:

- From the environment in the isolated space (temperature of the room $-20 \pm 0.1^{\circ} \mathrm{C}$, relative humidity $-63.6 \%$ ): on the porous metal hot plate heated up to $35^{\circ} \mathrm{C}$, where the temperature of the human skin and the sweat excretion physiological process were simulated simultaneously [in the device Sweating Guarded Hot Plate M259B (SDL International Ltd., UK)]. The air velocity in the test chamber was $0 \mathrm{~m} / \mathrm{s}$ and $1 \mathrm{~m} / \mathrm{s}$. The steady state of the heating temperature was reached after $470 \mathrm{~s}$ when the $3 \mathrm{~V}$ voltages were applied and $630 \mathrm{~s}$ for a $5 \mathrm{~V}$ voltage supply. Then, the

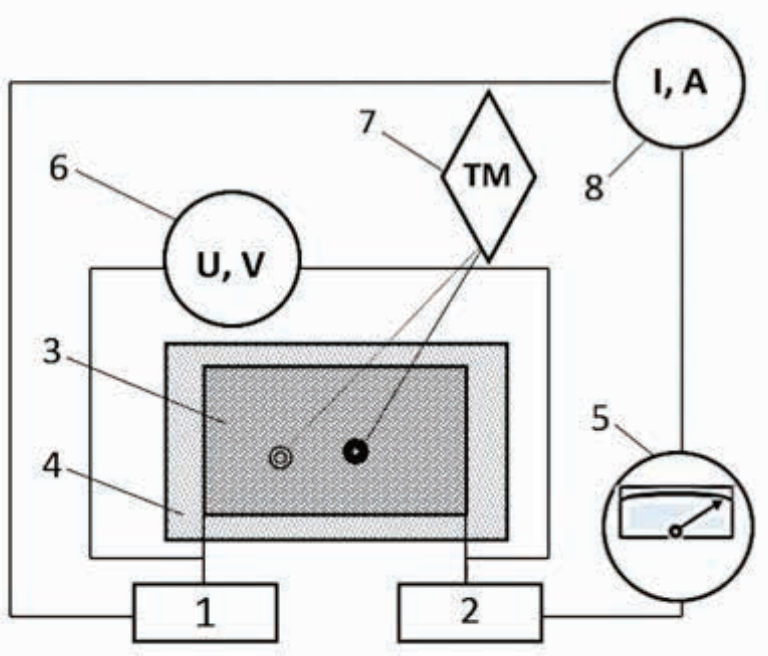

Figure 5. The principal scheme for testing the heating behaviour of the heating element: 1 and 2 - clamps; 3 - heating element; 4 - human skin/guarded hot plate; 5 - direct current power source Keithley series 2200, model 2200-20-5 (Tektronix Inc., USA); 6 - digital multimeter UNI-T $^{\circledR}$ DT-890C $^{+}$(Uni-Trend Technology Limited, China); 7 - twowire thermocouple type sensors $2 \times \mathrm{NTC}$ Type $\mathrm{N}$ with ALMEMO $^{\circledR}$ 2470 series universal measuring instrument; and 8 - digital multimeter UNI-T ${ }^{\circledR}$ UT33C. power source was switched off and the heating element was cooled out.

- From the environment in the insulated space (room temperature $-20.5 \pm 0.1^{\circ} \mathrm{C}$, relative humidity $-34 \pm 1 \%$ ): on the back of the real human by wearing two different variants of clothing: (1) t-shirt and (2) t-shirt + jumper. The values of thermal resistances $\left(R_{c t}\right)$ of garments were determined according to EN ISO 11092 [26]: t-shirt $-0.030 \mathrm{~m}^{2} \mathrm{~K} / \mathrm{W}$ and jumper $-0.140 \mathrm{~m}^{2} \mathrm{~K} / \mathrm{W}$.

As the application field of developed textile heating elements are heating textile products for sports, recreational activities, or improving health of the elderly or disable people, the testing environmental conditions were simulated as in reality, i.e., room temperature.

In the course of the research, the first one (external), the thermocouple sensor, was fastened on the outside of the heating element. The second one, the (internal) thermocouple sensor, was embedded between porous metal hot plate/human skin and the heating element (see Figure 6). The internal sensor recorded the temperature of the heated porous metal plate/ human skin. The external sensor recorded the temperature of the external surface of the heating element. According to values of the recorded temperature, the heat loss from the heating element to the environment can be estimated.

\section{Results and discussions}

A silver-coated yarn is a polymeric yarn that obeys the Ohm's law and has a material breakdown point depending on the glass transition temperature. Therefore, to ascertain this point, due to increase in current, voltage, and length of the conductive yarn (reduction in resistance), the investigations were carried out and presented in [27]. It was determined that the voltage of $9 \mathrm{~V}$ was the maximum securest value, which could be applied to fabrics without harm. Following that voltages of 3 and $5 \mathrm{~V}$ were used in these investigations, as more conductive yarns were involved in the production of the heating element.

As it is written earlier, the newly developed heating element has a homogeneous temperature distribution at the surface. The thermal images were taken using the thermal camera (spectral range 7.5-13 $\mu \mathrm{m}$ ) InfraCAM (Flir Systems AB, Sweden) when the power to different heating elements was applied (see Figure 7). Three (Figure $7 a-c$ ) out of four heating elements were manufactured by the Center for Physical Sciences and Technology (Lithuania) after detailed research of the market of heating elements, but only one is described and

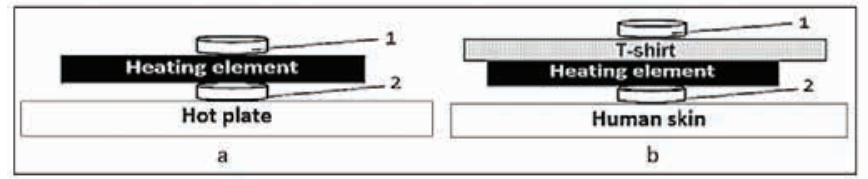

Figure 6. Principal measuring scheme of external (1) and internal (2) thermocouple sensor equipment on the (a) sweating guarded hot plate and (b) human skin. 


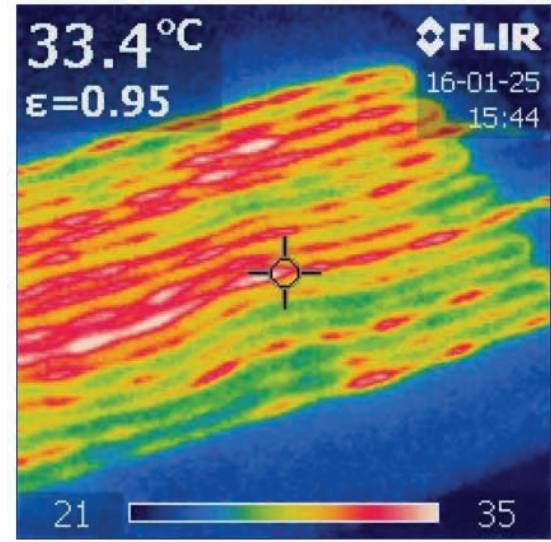

(a)

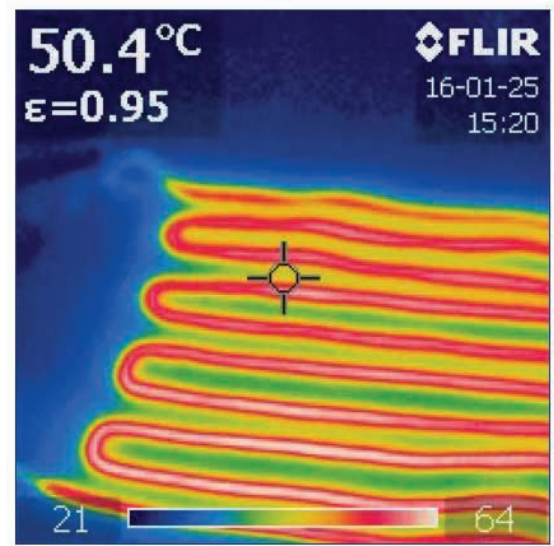

(b)

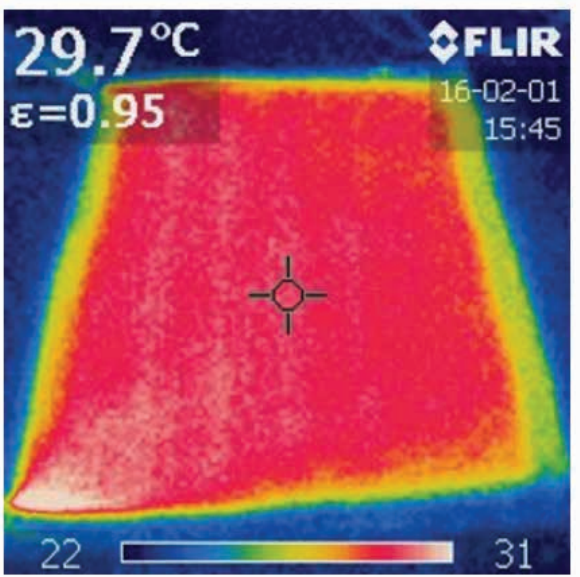

(c)

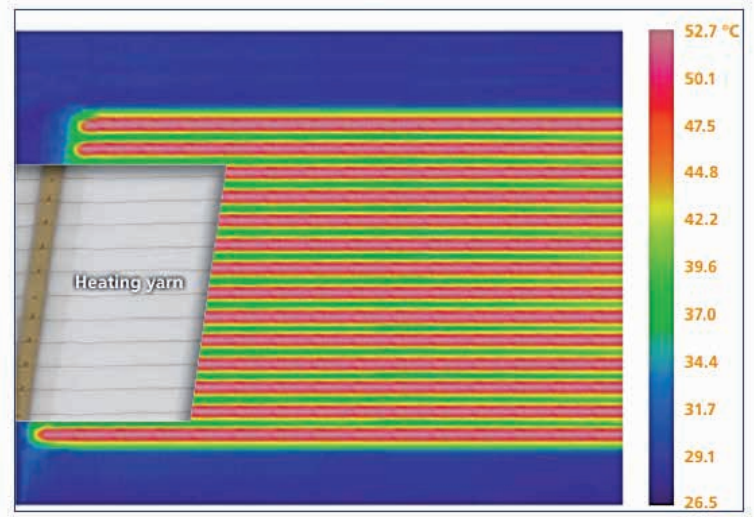

(d)

Figure 7. Thermal images of heating elements: (a) produced by using TPU-isolated, silver-coated polyamide Elitex ${ }^{\circledR}$ yarns; (b) produced by using continuous enameled copper wire; (c) produced by using four-ply, silver-coated, twisted polyester filament yarns Shieldex ${ }^{\circledR}$ inserted in the knitted fabric (the object of this research); and (d) produced by using SEFAR ${ }^{\circledR}$ PowerHeat fabric panel [28].

investigated in this paper, because it provided continuous and even heat distribution. The fourth heating element was taken as an example to show the maintaining heat distribution in the available heat elements of the industry.

In order to investigate the dependence of thermal efficiency of the heating element on the environmental conditions, experiments were carried out in an isolated chamber with no air flow and when air flow was $1 \mathrm{~m} / \mathrm{s}$.

The results were obtained as follows: the steady state of internal and external sensors in tests at different air flow speeds (at an applied voltage of $3 \mathrm{~V}$ and a constant current of $1.68 \mathrm{~A}$ ) was reached approximately at the same time, i.e., $470 \mathrm{~s}$. However, when a voltage of $5 \mathrm{~V}$ and a constant current of $2.8 \mathrm{~A}$ were involved; the steady-state temperature was reached only after $630 \mathrm{~s}$. The time to reach steady state significantly increases when a higher voltage is applied to the heating element.

It is seen from Figures 8 and 9 that the difference between the steady-state temperature registered by internal and external thermocouples is approximately $3^{\circ} \mathrm{C}$. Experiments have showed that despite the air conditions, i.e., wind speed, and the voltage applied, the temperature next to the skin will be $3^{\circ} \mathrm{C}$ higher than on the outside of the heating element (see Figures 8 and 9).
Also the temperature recorded by external thermocouples shows that some heat is released from the surface of the heating element: there is a tendency of temperature decrease from $3^{\circ} \mathrm{C}$ to $5^{\circ} \mathrm{C}$ while comparing temperatures reported by external and internal thermocouples (see Figures 8 and 9). A similar tendency of temperature decrease was recorded by Kayacan et al. in [29], while investigating heated panels of three- and four-ply steel-based fabric.

It is clearly seen from Figures 8 and 9 that despite the environmental conditions, on the application of a constant voltage, the heating/cooling effect shows a transient behavior. The same was observed by Hamdani et al. [7].

It is known from the literature review that human feels comfortable when the sensation temperature varies from $32^{\circ} \mathrm{C}$ to $37^{\circ} \mathrm{C}[20,30]$. When $3 \mathrm{~V}$ was fed to the heating element, during the experiment, the maximum steady temperature recorded by the internal thermocouple was $33.5^{\circ} \mathrm{C}$ (when air flow was $0 \mathrm{~m} / \mathrm{s}$ ). It is the minimum of comfortable temperature, so the voltage of $5 \mathrm{~V}$ and a constant current of $2.8 \mathrm{~A}$ were involved. The internal thermocouple registered $39.9^{\circ} \mathrm{C}$ (when there was no air flow in the isolated chamber) steady-state temperature - it is the temperature that could harm human body - and $37.03^{\circ} \mathrm{C}$ (comfortable temperature for humans) temperature, when a flow rate of $1 \mathrm{~m} / \mathrm{s}$ was used. So, according to the received results we can state that the voltage of $3 \mathrm{~V}$ can be applied for the heating element and it will give comfort and 


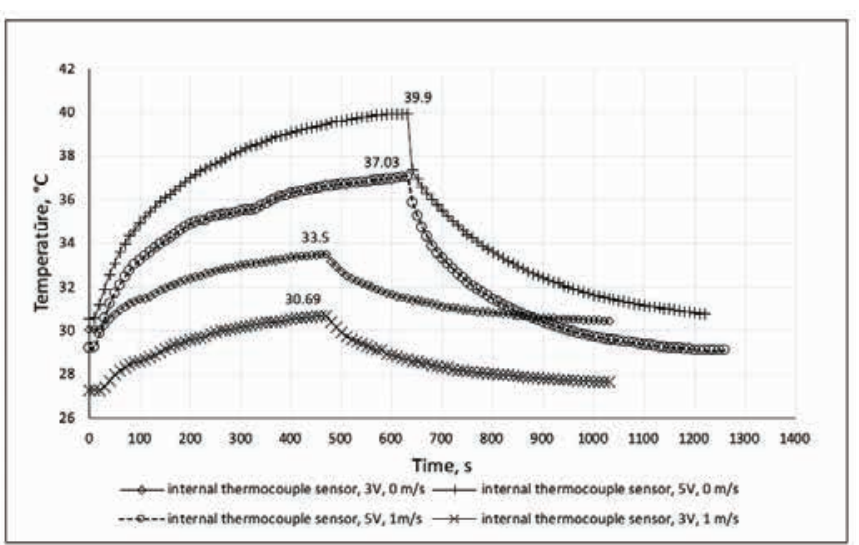

Figure 8. Influence of different conditions in chamber and applied voltage to the heating element on heating up and heat release dynamics of sweating hot plate

warm feelings to humans. The voltage of $5 \mathrm{~V}$ can be used only when the wind blows, because in an absolutely isolated chamber, when the air flow is zero, the temperature is high enough, which could do harm for human skin (see Figure 8).

Kayacan and Bulgun investigated the heating behaviour of panels containing stainless steel yarns in [16]. They received that four-ply heating pads reach the maximum temperature value of $60^{\circ} \mathrm{C}$ when electrical current for the circuit was supplied from a battery pack having a capacity of $12 \mathrm{~V}$. Also they concluded that, as expected, the heating levels of the different plies can be arranged as "four-, three-, two-, and oneply.

In order to investigate how humans will feel heat/warmth in real conditions, by wearing heating element with multiple layers of clothing, we carried out experiments on real humans with different clothing layers. Babus'Haq et al. [31] defined the main modes of the heat transfer between a human skin and its clothing ensemble: (1) conduction at the pressed contacts where the human skin touches the material; (2) conduction, convection, and radiation across the air gaps between successive layers of clothing and the skin; and (3) mass transfer of evaporated perspiration across the cavities.

The steady-state temperature was reached approximately after $330 \mathrm{~s}$ when a voltage of $3 \mathrm{~V}$ was applied to the heating element, which was laid on the real human skin and closed with an assembly of clothing. We can see from Figure 10 that the increase in the number of layers gives slighter cooling effect, when the heating element is switched off. The individual with only t-shirt will feel cold sooner compared to the individual who wears t-shirt with jumper. In addition, we can agree with the state of authors in [29] that the total thermal insulation value for each ensemble of more layers of the textile is higher than that of a single layer.

As results of heating are not very significant, compared to cooling temperature, we increased voltage to $5 \mathrm{~V}$. As it was predicted, the internal thermocouple registered steady-state temperature values of $38-40^{\circ} \mathrm{C}$, which were reached after approximately $620 \mathrm{~s}$ (see Figure 11). Here we can see obvious

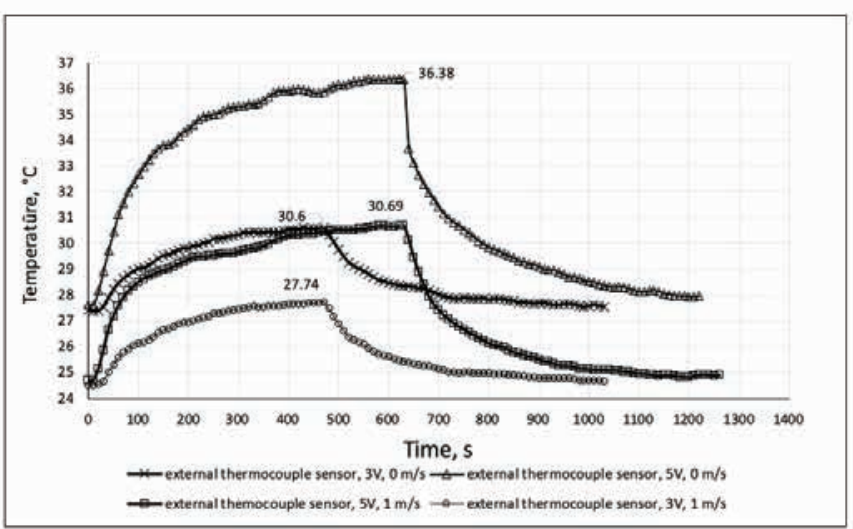

Figure 9. Influence of different conditions in the chamber and applied voltage on heating-up and heat-release dynamics of the outer surface of the heating element tested on a hot plate.

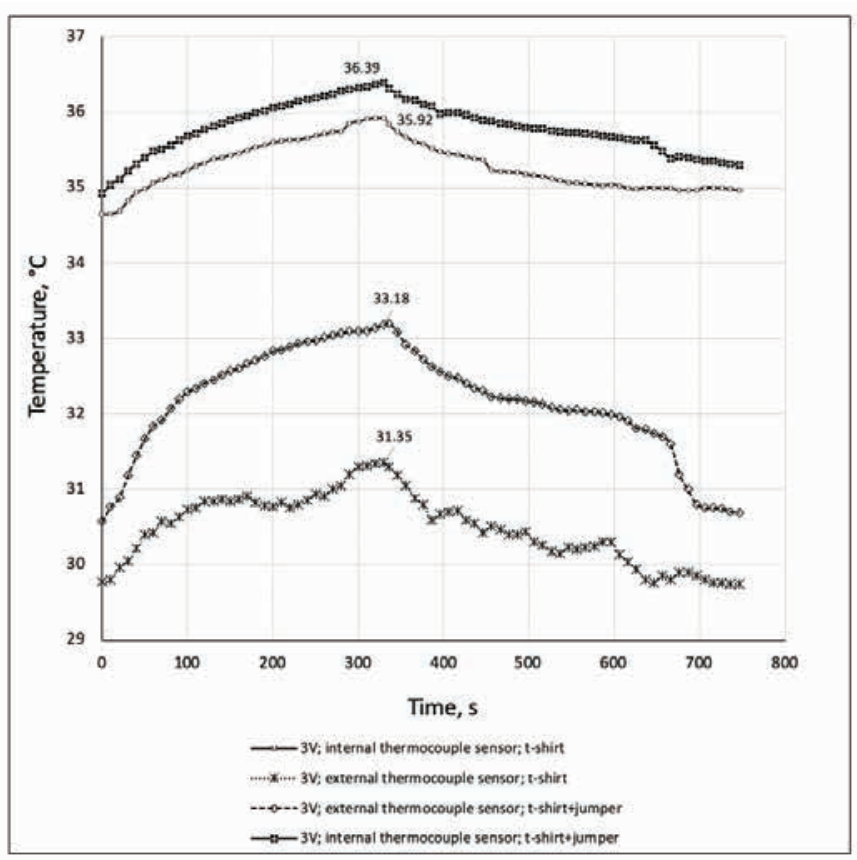

Figure 10. Recorded temperatures during heating-cooling processes of a heating element tested on a human skin at an applied voltage of $3 \mathrm{~V}$ and a constant current of $1.68 \mathrm{~A}$ depending on the layering of clothing.

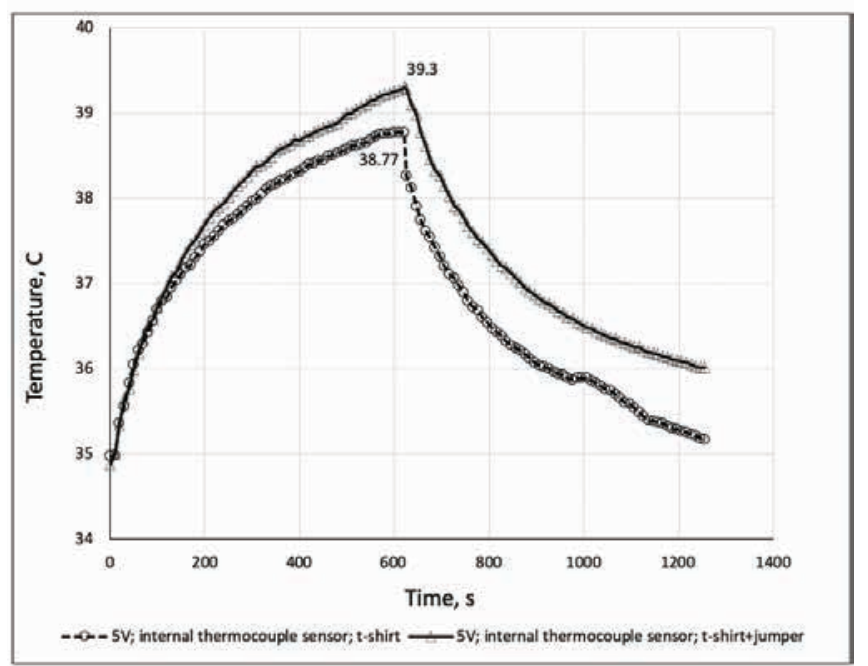

Figure 11. Recorded temperatures of human skin during the heatingcooling process of a heating element tested at an applied voltage of $5 \mathrm{~V}$ and a constant current of $2.8 \mathrm{~A}$ depending on the layering of clothing. 
rise of temperature while heating was turned on and distinct cooling effect when the heating element was switched off.

Data presented in Figures 10 and 11 show that at a voltage of $3 \mathrm{~V}$, the steady-state temperature registered with the internal thermocouple is very similar, despite the number and type of clothing to be worn. While when $5 \mathrm{~V}$ was used, the steady-state temperature of the human skin increases $1^{\circ} \mathrm{C}$ with increase of every garment layer.

It can be concluded from results presented in Figures 10 and 11 that the received test results are significant and depend on the number of layers. At $3 \mathrm{~V}$, the difference between temperatures is $0.47^{\circ} \mathrm{C}$ and at $5 \mathrm{~V}, 0.53^{\circ} \mathrm{C}$. Such a temperature change in human skin greatly affects the thermal sensation and metabolic rate. The temperature of $39^{\circ} \mathrm{C}$ is high and not comfortable for humans, but from approximately $35^{\circ} \mathrm{C}$ of temperature, humans feel warmth (see Table 1).

The result in Figure 12 shows that a slight decrease in outside temperature is seen when only t-shirts or t-shirts with jumper were on the humans.

Results in Figures 10 and 12 state that the warmth leaves the human skin and goes through the assembly of clothing quicker when the $3 \mathrm{~V}$ voltage was applied. It does not ensure that the heating element will give wanted warmth and comfort feeling to the individual. A higher voltage gives lesser loss of the warmth, but it can cause too hot and uncomfortable feeling to the individual.

\section{Conclusions}

An analysis of scientific and technical literature sources suggests that one of the main tasks in the design of products with heating elements is the creation of a flexible textile heating circuit. However, there is a lack of detailed information on the structure and technical details of the prototype heating circuits.

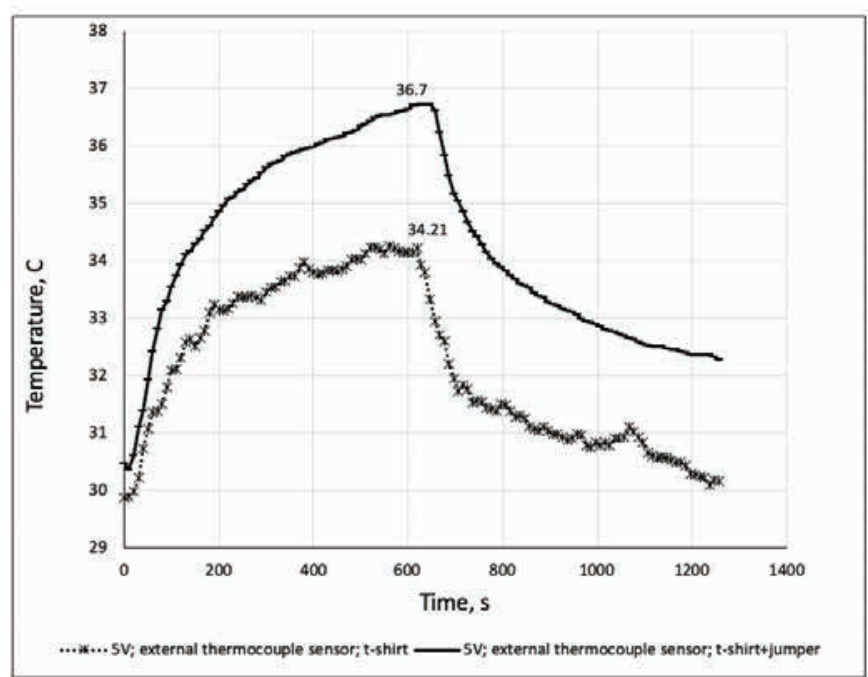

Figure 12. Recorded temperatures on the outer surface of a heated t-shirt during the heating-cooling process of a heating element tested on a human skin at an applied voltage of $5 \mathrm{~V}$ and a constant current of 2.8 A depending on the layering of clothing.
While using non-isolated yarns, scientific publications lack data on the protection of heating circuits from moisture and investigations of human skin temperatures during heating and cooling.

The electrically conductive textile heating element of the new structure was designed and manufactured using PET silverplated yarns, which formed a heating circuit of natural size, consisting of different parallel circuits closed by the electrical circuit. The optimal technical circuit had an analog heating circuit, which distributed heat evenly.

It was concluded during this research that under certain environmental conditions $(20 \pm 0.6)^{\circ} \mathrm{C}$ :

- heating efficiency of the heating element depends on the environmental conditions: testing on a human skinsimulated porous hot plate and increasing the air flow speed from 0 to $1 \mathrm{~m} / \mathrm{s}$ when applying an voltage of $3 \mathrm{~V}$, the heating temperature of the hot plate decreases approximately $8.4 \%$, i.e., from $33.5^{\circ} \mathrm{C}^{\circ}$ to $30.69^{\circ} \mathrm{C}$. When the $5 \mathrm{~V}$ voltage was applied, the heating temperature of the plate reduced by approximately $7.2 \%$, i.e., from $39.9^{\circ} \mathrm{C}$ to $37.03^{\circ} \mathrm{C}$.

- heating effect of the heating element depends on the combination of wearable layers of clothing: testing on a real human skin at a voltage of $3 \mathrm{~V}$, the skin is warmed up to $35.92^{\circ} \mathrm{C}$ by wearing only a t-shirt, and up to $36.39^{\circ} \mathrm{C}$ by wearing two clothing components - a t-shirt and a jumper. Supplying a $5 \mathrm{~V}$ voltage to the heating element, the minimum achieved skin temperature when wearing only a t-shirt is $38.77^{\circ} \mathrm{C}$ and the maximum is $39.3^{\circ} \mathrm{C}$ when wearing two clothing components. This indicates that, in the specified test conditions, a $3 \mathrm{~V}$ voltage supply is sufficient to ensure that the heating element is efficiently operated and human feel comfortable warmth by wearing the heating element.

- It was found that in all test cases, the heat generated by the heating element is directed not only toward the human skin, as the external surface of the heating element also heats. The achieved steady-state heating up temperature range of the outer surface of the heating element was tested on a hot plate $\left(27.74-36.38^{\circ} \mathrm{C}\right)$ and on the human skin $\left(31.35-36.7^{\circ} \mathrm{C}\right.$. These temperature parameters can be interpreted as heat loss from the heating element surface into the environment. Heat loss can be reduced by increasing thermal insulation properties of the outer layer of the heating element or using layered clothing. This would increase the continuous operating time of power source.

\section{Acknowledgments}

The authors declare that there is no conflict of interest regarding the publication of this paper. No data were used to support this study. This article was supported by the Research Council of Lithuania, agreement No. TEC-04/2015. 


\section{References}

[1] CEN/TR 16298: 2011. Textiles and textile products Smart textiles - Definitions, categorization, application and standardization needs.

[2] Stoppa, M., Chiolerio, A. (2014). Wearable electronics and smart textiles: a critical review. Sensors, 14(7), 1195711992.

[3] De Mey, G., Özçelik, M., Schwarz, A., Kazani, I., Hertleer, C., et al. (2014). Designing of conductive yarn knitted thermal comfortable shirt using battery operated heating system. Journal of Textile and Apparel/Tekstil ve Konfeksiyon, 24(1), 26-29.

[4] Strazdienè, E., Dobilaité, V. (2007). Techninès Tekstilès gaminiai ir protingoji apranga. Šiauliai: VŠl Šiauliu universiteto leidykla, Lithuania, p. 168, DOI: 10.5755/ e01.9786090204634.

[5] Vargas, S. C. (2009). Smart Clothes - Textilien mit Elektronik. Was bietet der Markt der Intelligenten Bekleidung? Hamburg Diplomica® Verlag $\mathrm{GmbH}$, p. 314, ISBN: 978-3-8366-7230-6.

[6] Šahta, I., Baltina, I., Truskovska, N., Blums, J., Deksnis, E. (2014). High performance and optimum design of structures and materials. 137, 91-102, DOI: 10.2495/ HPSM140091.

[7] Hamdani, S. T. A., Potluri, P., Fernando, A. (2013). Thermomechanical behavior of textile heating fabric based on silver coated polymeric yarn. Materials, 6(3), 1072-1089.

[8] Locher, I. (2006). Technologies for system-on-textile integration, Doctoral thesis, ETH No. 16467, Swiss Federal Institute of Technology: Zürich, p. 121, DOI: 10.3929/ ethz-a-005135763.

[9] Sezgin, H., Bahadir, S. K., Boke, Y. E., Kalaoglu, F. (2012). Effect of different conductive yarns on heating behaviour of fabrics. In: PMUTP International Conference: Textile \& Fashion, Access to Internet: http://textileconference.rmutp. ac.th/wp-content/uploads/2012/10/009-Effect-of-DifferentConductive-Yarns-on-Heating-Behaviour-of-Fabrics.pdf.

[10] Ding, J. T. F., Tao, X., Au, W. M., Li, L. (2014). Temperature effect on the conductivity of knitted fabrics embedded with conducting yarns. Textile Research Journal, 84(17), 18491857.

[11] Roell, F. (1996). U.S. Patent No. 5,484,983. U.S. Patent and Trademark Office (Washington, DC).

[12] Lee Sandbach, D., Burkitt, J., Walkington, S. M., Crispin, P. G. (2008). Knitted sensor. United States Patent Application Publication-2008.-Nr US, 7377133.

[13] Petcu, I., Agrawal, P., Curteza, A., Visser, R., Brinks, G. et al. (2012). In 12th AUTEX World Textile Conference, Faculty of Textile Technology of the University of Zagreb.

[14]Poboroniuc, M. S., Curteza, A., Cretu, V., Macovei, L. (2014). Designing wearable textile structures with embeded conductive yarns and testing their heating properties. In: International Conference and Exposition on Electrical and Power Engineering (EPE), p. 778. DOI: 10.1109/ICEPE.2014.6970016.

[15] Mečnika, V., Hoerr, M., Krivinš, I., Schwarz, A. (2014). In rural environment. Education. Personality (REEP) Proceedings of the International Scientific Conference (Latvia). Latvia University of Agriculture.
[16] Kayacan, O., Bulgun, E. Y. (2009). Heating behaviors of metallic textile structures. International Journal of Clothing Science and Technology, 21(2/3), 127-136.

[17] Ohgushi, K., Hijiri, M., Kitazawa, Z. (1991). U.S. Patent No. 4,983,814. U.S. Patent and Trademark Office (Washington, $D C)$.

[18] Tao, X. (2004). Wearable electronics and photonics. Woodhead Publishing, p. 256. ISBN 978-1-85573-605-4.

[19] Bai, Y., Li, H., Gan, S., Li, Y., Liu, H., Chen, L. (2018). Flexible heating fabrics with temperature perception based on fine copper wire and fusible interlining fabrics. Measurement, 122, p. 192-200.

[20] Pan, N., Gibson, P. (Eds.). (2006). Thermal and moisture transport in fibrous materials. Woodhead Publishing Series in Textiles No. 56 (Cambridge, England). p. 632, ISBN: 9781845690571.

[21] Koralewski, H. E. (2006). Energiehaushalt und Temperaturregulation. Berlin, Charité Bioinformatic SS Cluster B4, 1. Access in internet: https://klinphys.charite. de/bioinfo/2_p-skripten/b4_b_waermehaushalt.pdf.

[22] Wiezlak, W., Zielinski, J. (1993). Clothing heated with textile heating elements. International Journal of Clothing Science and Technology, 5(5), 9.

[23] Woods, K., Bishop, P., Jones, E. (2007). Warm-up and stretching in the prevention of muscular injury. Sports Medicine, 37(12), 1089-1099.

[24] McCann, J. (2013). Smart protective textiles for older people. In Book smart textiles for protection. Woodhead Publishing Series in Textiles Woodhead Publishing Limited, pp. 253-273.

[25] Palamutcu, S., Goren, I. (2015). Functional textile preferences of elderly people. Mediterranean Journal of Social Sciences. 6(2S5), 279-285.

[26] EN ISO 11092: 2014. Measurement of thermal and watervapour resistance under steady-state conditions (sweating guarded-hot plate test).

[27] Varnaitè-Žuravliova, S., Baltušnikaitè-Guzaitienè, J., Valasevičiūtè, L., Verbienè, R., Abraitienè, A. (2016). Assessment of electrical characteristics of conductive woven fabrics. American Journal of Mechanical and Industrial Engineering, 1(3), 38-49.

[28] Filter components customer info 23 SEFAR. Access via internet: https://www.sefar.com/data/docs/en/5662/SFPDF-Smart-Fabrics-Cl-23-PowerHeat-EN.pdf?v=1.2.

[29] Kayacan, O., Bulgun, E., Sahin, O. (2008). Implementation of steel-based fabric panels in a heated garment design. Textile Research Journal, 79(16), 1427-1437.

[30] Wang, F., Gao, C., Kuklane, K., Holmer, I. (2010). The review of technology of personal heating garments. International Journal of Occupational Safety and Ergonomics (JOSE), 16(3), p. 387-404.

[31] Babus'Haq, R. F., Hiasat, M. A. A., Probert, S. D. (1996). Thermally insulating behaviour of single and multiple layers of textiles under wind assault. Applied Energy, 54(4), 375391. 